\title{
Positive Effect or Negative Effect? Judging the Social Impact of Guanxi in the Perspective of Traditional China Culture
}

\author{
Ruihui Han \\ Humanities School, Jinan University, Zhuhai, Guangdong Province, China \\ Qingdian Han \\ Agriculture and Forestry Science College, Linyi University, Linyi, Shandong Province, China \\ *Corresponding Author: Ruihui Han, Humanities School, Jinan University, Zhuhai, Guangdong \\ Province, China. \\ Received Date: 09-04-2017 \\ Accepted Date: 18-04-2017 \\ Published Date:12-04-2017

\begin{abstract}
Understanding and judging guanxi in the perspective of traditional China culture is critical, as guanxi is more complicated than the western social network and cannot be judged by the western social values. The previous researches about guanxi tended to judge guanxi in with the western social values, and that cannot give the satisfactory conclusion because of the complication of guanxi in China culture background. The aim of this study was to judge the social impact of guanxi in the perspective of China traditional Confucian culture. Results showed that guanxi in China Confucian culture stirs up the conflicts and incompatibility. Although guanxi originated from and justified by the Confucian culture, having some advantages, however, the guanxi culture results in the conflict and incompatibility within the Confucian culture. So, even judged by the traditional Confucian culture, guanxi still has many deflects. Besides, guanxi is also challenged by the globalization.
\end{abstract} \\ Kevwords: guanxi: Confucian culture: Social impact: interpersonal relationship: social network.
}

\section{INTRODUCTION}

China interpersonal relationship is different from that in the western world. In order to distinguish the unique interpersonal relationship in China, the interpersonal relationship is called as guanxi. In the daily life, China people deem guanxi as not only the interpersonal relationship, but more than about that generally. In many cases, guanxi means the special privilege based on hidden rules, and is inevitably involved with corruption and unfair play. However, on the other hand, sometimes guanxi is also regarded as friendship, which will promote the work efficiency.

So the question is, whether guanxi is a positive or negative factor in China society. Many researchers have given their answers about such question. Because of guanxi, in a company, China supervisors will allocate the rewards according to personal relationship but not performance merits, so, in this case, guanxi will lower trust in the supervisors (Chen, Chen, \& Xin, 2004). In the rural area, reliance on guanxi will limit the upward mobility and channel the women labors to low-paid gender specific jobs(Chen, Chen, \& Huang, 2013).

Another group of researchers found that guanxi has the advantages for society and work efficiency. For example, Chinese workers have much trusts with the one having familiar ties and just as the friendship, so they can improve the working efficiency (J. Der Luo, 2011). When the interpersonal relationship is based on guanxi, Chinese executives will have more trust than when they connect each other based on regular work ties (Farh, Tsui, Xin, \& Cheng, 1998). Guanxi also facilitates the company competition, 
and building and using personal connections is critical to the company advantage and superior performance (e.g. Y. Luo, 2001; Peng \& Luo, 2000; Park \& Luo, 2001)

There are still other researchers believes that the guanxi is double edged sword, which can bring both positive and negative results (Chen et al., 2013).

The debate of results of guanxi continues with the study of guanxi. However, there is no research discuss on the question from the perspective of China culture. If we discuss on such question according to China history and culture, and judge such question basing on the China history and culture. We can get the new understanding on the question.

This paper set out to investigate the results of guanxi in China in the perspective of China culture and history. Guanxi is a kind of China cultural phenomenon. It rooted in Chinese culture and has formed and reinforced in two thousand years (Fei, 2002). Some researchers, such as Boisot and Child (1996) argued that guanxi can lead the economic reform to a clan economic form. Although the economic institution reform took place and continued in recent years, as a kind of culture, the guanxi will not change easily and must be incorporated into the new institutional system. In other market economies, such as Singapore, personal relationship, or guanxi, is still critical to business and employment relationship (Bian \& Ang, 1997). It can find that guanxi exerted the influence in both ancient times and contemporary times. In the future, gaunxi is still an important phenomenon prevailing in many aspects of China society and economy.

The central question this paper set out to investigate is the results of guanxi in the perspective of China history and culture. In other words, this paper will judge the results of guanxi in China history and culture, but not under the criterion of western culture and history.

In order to discuss such problem, we should do the following works: 1) investigating the origin of guanxi in China history; 2) explaining the relationship between guanxi and China culture; 3 ) describing the function of guanxi in contemporary China economy.
This paper will shed new light on the understanding of guanxi. Previous researches often discussed on the problems with the focus on the western criterion, while this paper will discuss the problem in China culture system and history.

Guanxi is the most critical concept in this paper. Throughout this paper, the term "guanxi" will refer to a kind of social connection, according to which the participants can derive the benefit from it. Guanxi in China language has many different meanings. For example, the guanxi could refer to the friendship, the interpersonal connection, or the interaction between the social individuals, as Chinese language is ambiguous, so some researchers notices the word "guanxi " has multiple meanings: a) the relationship of one group people share a group status or have relationship with a common person; b) the connection between the frequent contacted people; and c) the rare connection between the acquainted individuals(Bian, 1994). If we want to judge the guanxi's effect, we should analyze the guanxi according to the guanxi's function. So here we give the definition to the word "guanxi" according to the function of it. The direct function of guanxi is to get the benefit by the social network, therefore, it is suitable to define the concept to be the social connection, by which the participants can get the benefit from it.

The paper is structured as following: this paper begins by the brief description of guanxi's origin in China. It will then compare guanxi with the western style interpersonal relationship. The third part of the paper is to deal with the effect of guanxi on individual and group developments.

\section{The ORIGIN OF GUANXI In ChINA}

Guanxi rooted in the Confucian culture. The Confucian influence on China interpersonal relationship has continued for two thousand years, however, the systematic study on guanxi came into being not until 1970s, when the reform and opening policy was applied in China(Y. Zhang \& Zhang, 2006). Without the reform and opening policy in China, few people will notice the different between the interpersonal relationships in China and the western world, as China people had adopted to such style of interpersonal relationship, without knowing the 
uniqueness of it. For two thousand years, Confucian culture existed in China as the dominant culture, without knowing other kinds of culture deeply, people rarely notice the difference between Confucian culture and other cultures.

The morality of Confucian culture determine the interpersonal relationship, or guanxi in China. The eastern Asian communication pattern is different from that in the North American, because, in eastern Asia, more emphasis is put on the interpersonal relationship (Yum, 1988). The fundamental principal of Confucianism is humanism. Humanism in Confucianism means the warm reciprocal relationship among individuals. In China history, the first meaning of humanism meant the loving for the family numbers (Jing, 2012). Such humanism in the family territory is also extended to the social territory. According to Confucianism, the humanism should be regardless of the classes and other identity. Here, Confucian gave a revolutionary explanation for humanism, in that he extended the territory of humanism's object to whole society. With Confucian's revolutionary explanation, humanism became the fundamental principle of interpersonal relationship.

Humanism influences the interpersonal relationship deeply and profoundly in China. As the Confucianism is the most fundamental thoughts for two thousand years, and the humanism is the foundation of Confucian thoughts, the humanism will also exert the fundamental influence on the interpersonal relationship in China.

Justice is the second fundamental principle of Confucianism, which also influences the interpersonal relationship in China. According to Confucianism, the action complies with the morality, or humanism, is deemed as justice. As the humanism is the most fundamental principle in Confucianism thoughts, the morality is decided by the humanism. So here it can be found that the good interpersonal relationship is critical to the concept of "justice". In other words, the compliance to "justice" is determined by whether or not acting for the humanism.

Other three Confucian values also relates to the ethics, morality and social practice. Etiquette, according to Confucianism, refers to the practice of morality. Etiquette means not only the politeness in the western world, but also the other practice of morality. Etiquette happens among the interpersonal relationship, so etiquette is a kind of social activities. Wisdom does not refer the knowledge or capacity of judging. According to Confucianism, wisdom is also about the ethics and morality. It includes the conscience, with which the individual can judge the evil and goodness. The last important five values of Confucianism is faith. Faith in Confucianism means honesty and credit.

From aforementioned five values, we can find that such values are all about the interpersonal relationship. Different from other thought schools in ancient China, Confucian school pay extreme attention to interpersonal relationship. Other thought schools, such as legalist or Mohist school, focus on law and technology respectively. No other thought schools in ancient China pays so much attention to interpersonal relationship as Confucian school.

Guanxi, a unique Chinese interpersonal personal relationship, is forged during the process. Confucianism thought spread in China and influenced China culture profoundly. The pattern of politics in ancient China is characterized by rule by man but not rule by law. Tradition of rule by man is caused by the Confucianism thought, and it reinforced the Confucianism thought in turn. That is, Confucianism thought, as a kind of knowledge, and political institution, as a kind of power, reinforced each other in ancient China history.

Above all, the mainstream and traditional thought, Confucian engendered the guanxi custom and culture. As a culture, guanxi culture influences the political institution in ancient China, and will not change in short period. Even in Singapore, where many ethnic Chinese occupy the most population where the modern western market economy prevails, the guanxi is also got the extremely attention by ethnic Chinese than other ethnic groups, but meanwhile, guanxi is also in the vestigial form and overridden by other considerations among Chinese in Singapore, as Singapore is highly market economy developed (Tan \& Snell, 2002). The example of Singapore suggests that the political and economic institution can change the position of guanxi, but as a kind of culture, guanxi persists in Chinese 
population constantly, because guanxi is the result of Confucian thought, which is the traditional and mainstreaming culture in China.

The Difference BeTWEen GuAnXI AND WESTERN STYLE INTERPERSONAL RELATIONSHIP

China guanxi is more complicated than western social network. Western social network, or the interpersonal relationship discussed here, is dyadic, however, guanxi subsumes not only dyadic interpersonal relationship, but also the leader-number-exchange and the relationship making at all levels (Chen et al., 2013). In this case, guanxi involves with more interests of the participants.

One obvious feature of guanxi that different from western interpersonal relationship is that guanxi is more humane than the western interpersonal relationship, which is more instrumental. The guanxi in China can be divided into two kinds: one is affectionate guanxi, and another is instrumental guanxi. The former is typical in guanxi among family numbers, and the latter is exampled by the business guanxi. Much guanxi is used for the interest and benefit, so guanxi in many cases is also instrumental as the western interpersonal relationship is. Therefore, some researchers dealt with guanxi problem research in the perspective of economic transaction cost (Lovett, Simmons, \& Kali, 1999). But it also needed to point out that guanxi has more affection involved than western social network and longer reciprocal relationship.

In the business relationship, guanxi plays a moreelationship oriented role than the western interpersonal relationship. For guanxi, the personal relationship among the business transaction is far more important than the inter-firm relationship during the transaction process (Berry, 2002). The business relationship is often the outcome of the personal relationship (Wang, 2007). During the business transaction process, the more investment is needed for the affection cultivation.

In contrast to the western social network, in which weak tie and the hole of the law enable the facility of some individuals' getting benefits, guanxi should be strong tie in order to get the benefit. For example, managers who have the social networks consisted of strong ties will be more successful than the others who have the weak tie social networks (Xiao, Tsui, Administrative, Quarterly, \& Mar, 2007). So the western mangers are advised to learn guanxi in China in order to get good performance in business (Y. Luo, Huang, \& Wang, 2012). Guanxi contributes a lot to the employment seeking in human resource market in China. Re-employment was positively related to the number of the relatives in same generation in the same city(Giles, Park, \& Cai, 2006). In the un-farm employment, the job seeking is positively related with the kinship guanxi ties, or in other words, family members and relatives (X. Zhang \& Li, 2003). Family members and relatives belong to the strong tie.

Guanxi is different from the social network in that guanxi does not promise the roughly equal value in the reciprocal exchange between the participants. However, in the social network in the western, the participants will get the roughly equivalent benefits from each other (Powell, 1990), especially of the material benefits. However, the benefits of the participants in guanxi will be more complicated. For example, some benefits cannot be evaluated by money or materials, such as mianzi and renqing. Mainzi is an intangible wealth in China society, which is better translated as face. It is related with the material wealth and social status of the individual, so one should keep mianzi to expand the social network (Yeung \& Tung, 1996). Renqing is also a kind of intangible social capital, which can enable the individual to get the benefits s/he wants. It is in the social exchange among the individuals. As the individuals weave the guanxi network, they are also bound by renqing(Yeung $\&$ Tung, 1996). Both renqing and mianzi are intangible and cannot be evaluated by material or money. However, mianzi and renqing compose the main part of guanxi network. So in guanxi network in China society, it is hard to calculate the benefits and promise the equivalent benefits of the reciprocal participants.

Another important factor that differentiate the China guanxi from the western social network in that guanxi has longer effect on all the participants. The interpersonal relationship, 
including that of China, is long-term relationship (Yum, 1988). Or even in a sense, one individual is forever indebted for another one's help, and in turn such will be the debtor for another(Yum, 1988). So guanxi will continue for a long time.

From aforementioned differences, one will find that China guanxi is more complicated than the western social network. China guanxi is difficult to be calculated, long-term interaction, and more humane or affection-involved. Besides, guanxi, the China style social network, plays more critical role in the company and individual performance, is more participants involved. The strong tie guanxi is especially better for the performance.

The next section will deal with the impact of guanxi on individual and society in the view of Confucian thought, the main traditional thought in China. They purpose of this section is to discuss on the different impacts of guanxi on individual and society respectively. Guanxi is associated with corruption occasionally in the perspective of western legal view. However, as discussed above, the guanxi is different from western social network greatly, so it is necessary to judge the problem in China traditional culture view.

JUdGING THE GUANXI'S IMPACTS ON SOCIETY AND INDIVIDUALS IN THE Perspective of China Traditional Culture

The main traditional culture in China is the Confucianism, which has the religious status in China, so if we want to judge on the guanxi impacts, we should make clear China traditional culture.

Besides aforementioned Confucianism values, humanism, justice, etiquette, wisdom and faith, there are many other values in the Confucianism. The other values include wen(moderation), liang (benevolence), gong (respect), qian (humility), rang (modesty) et al.. From those values, it can be found that the traditional Confucian pays much attention to enhance the good personal relationship. Confucianism focuses on the self-cultivation, development of moral values, but not the profit (Chan, 2008). On the other hand, Confucianism is of the commercial activities or law, but of human relationship.
The reciprocity is critical interpersonal relationship principle in Confucian thought. From the values we aforementioned, all the values is related to doing goodness to others. There is a famous proverb in Confucian thought: "Do not do to others what you do not want them to do to you" (Analects, Book XV, Number 23). There are other proverb in Confucian thought about reciprocity, such as:

What a man dislikes in his superiors, let him not display in the treatment of his inferiors: what he dislikes in inferiors, let him not display in the service of his superiors. (The Great Learning, X, ii).

The Confucian reciprocity can permeates in every aspect of China society. However, the most important lieu to imbed the reciprocity in is family, so the favoritism should towards family numbers (Chan, 2008).

Since the family numbers are the object of objects, the individuals should first work for the families they belonged to, then the other groups of society. The other groups include the factories, companies, or units s/he belonged to. In other words, the individuals' service center is the families, then the other groups according to distances between the $\mathrm{s} / \mathrm{he}$ and the groups. The family is the closest group s/he belonged to; it is also the center of guanxi.

Therefore, guanxi and the Confucian values are compatible with each other. The Confucian values justifies the guanxi; on the other hand, guanxi culture is originated from Confucian values. It is natural that the guanxi can exist in China history for more than two thousand years in this condition.

But, it is well known that guanxi has many disadvantages. favors the individual in the cost of society(Fan, 2012). Besides, corruption and bribery are among the most associations of guanxi (Dunfee \& Warren, 2001). Introduction business, the companies, especially the private companies, try to maintain the good guanxi with some corrupted officials, in order to enhance the economic performance. But it is still need the considerable cost, or the more cost in recent economic transition, to secure the political protection and access to the scarce resource (Park 
\& Luo, 2001). Although the reliance on guanxi has declines to some extent with the economic transition, guanxi still one of the critical culture aspects influences China society.

There are some values advocated by Confucianism, such as zhong(loyal), however, such value and other values of Confucianism are in conflict. There is famous proverb in China: "zhong xiao buneng liangquan."(Loyal and filial piety cannot be attained meanwhile). Filial piety is centered in the family, or to be accurate, the parents; loyal is for the emperor. The individual cannot serve the parents and emperor satisfactorily in the same time. The cause of the phenomenon is that the different distances between the different groups and the individuals.

The conflicts are inherent in Confucian tradition, just as the aforementioned proverb means. In ancient times, "Loyal and filial piety cannot be attained meanwhile". The conflicts continues in modern and contemporary times, in that the individual treats the different groups with different favoritisms or attitudes. In the planned economy period, the one who had the closer guanxi with officials who allocate the resources could be easier to get the scarce resources. In contemporary times, the firms can get the scarce resources by guanxi with some officials. The firms, especially the private firm, substitute the formal connection to government with the inform connection, guanxi, as the main connection. They relies heavily on guanxi for protection and gives more unreciprocated gifts than the state-owned and other kinds of companies(Dunfee \& Warren, 2001). While at the same times, the satisfactions of the small groups are in the cost of the large groups in modern and contemporary times.

The main tradition of Confucian thought cultivated and justified guanxi thought and practice, however, it still stirred up the beneficial conflicts among the different groups. Especially in the economy globalization period, guanxi practice and thought cannot meet the requirement of the globalization.

The shortcomings and stirred conflicts are inherent in the Confucian thought and practice. Although some researchers noted the advantages of guanxi, such as more trust in the economic transition period with guanxi to overcome the uncertainty(Galaskiewicz \& Wasserman, 1989), the guanxi still challenged by the globalization, which emphasizes the legality and contract. The enhancement of China economic and political institutions also contributes to the fading of guanxi in economic activities in recent years.

\section{CONCLUSION}

This study set out to judge the guanxi culture in Confucian cultural tradition. It has discussed the origin of guanxi in the perspective of Confucian culture. Confucian culture gives birth to guanxi culture in China. This study has also compared the guanxi culture with the western social network. It can be found that the guanxi is more complicated than western social network with more associations. So it is ambiguous to judge guanxi with western social values. Therefore, this study judge the impact of guanxi on society in the perspective of traditional Confucian culture. It can be found that, in the Confucian culture, there is inherent conflict and incompatibility about the values the Confucian insists. Guanxi, which originated and is justified in the Confucian culture, set the conflict and the incompatibility. Guanxi creates the different groups with the different attitudes toward such groups respectively, so the evaluations of such different groups are in conflict and is incompatible with each other. Although guanxi culture has many advantages, it is challenged by such value conflict and the recent globalization. This study has contributed a deeper insight into the social impact of guanxi with traditional Confucian culture.

\section{REFERENCES}

[1] Berry, L. L. (2002). Relationship Marketing of Services Perspectives from 1983 and 2000. Journal of Relationship Marketing, 1(1), 59-77. https://doi.org/10.1300/J366v 01n01_05

[2] Bian, Y. (1994). Guanxi and the Allocation of Urban Jobs in China. The China Quarterly, 140, 971-999. https://doi.org/ 10.1017/S0305741000052863

[3] Bian, Y., \& Ang, S. (1997). Guanxi Networks and Job Mobility in China and Singapore. Social Forces, 75(3), 981-1005. https://doi.org/10.1093/sf/75.3.981 
[4] Boisot, M., \& Child, J. (1996). From Fiefs to Clans and Network Capitalism: Explaining China's Emerging Economic Order. Administrative Science Quarterly, 41(4), 600-628. https://doi.org/ $10.2307 / 2393869$

[5] Chan, G. K. Y. (2008). The relevance and value of confucianism in contemporary business ethics. Journal of Business Ethics, 77(3), 347-360. https://doi.org/10.1007/s10551-007-9354-Z

[6] Chen, C. C., Chen, X. P., \& Huang, S. (2013). Chinese Guanxi: An integrative review and new directions for future research. Management and Organization Review, 9(1), 167-207. https://doi.org/10. 1111/more. 12010

[7] Chen, C. C., Chen, Y.-R., \& Xin, K. (2004). Guanxi practices and trust in management: A procedural justice perspective. Organization Science, 15(2), 200-209. https://doi.org/10.1287/ orsc. 1030.0047

[8] Dunfee, T. W., \& Warren, D. E. (2001). Is guanxi ethical? A normative analysis of doing business in China. Journal of Business Ethics, 32(3), 191-204. https://doi. org/10.1023/A: 1010766721683

[9] Fan, Y. (2012). Guanxi 's Consequences : Personal Gains at Social Cost Guanxi' s Personal Consequences: at Social Gains Cost. Journal of Business Ethics, 38(4), 371-380.

[10] Farh, J.-L., Tsui, a. S., Xin, K., \& Cheng, B.-S. (1998). The Influence of Relational Demography and Guanxi: The Chinese Case. Organization Science, 9(4), 471-488. https://doi.org/ 10.1287/ orsc.9.4.471

[11] Fei, X. (2002). From the Soil: The Foundations of Chinese Society. Berkeley: University of California Press.

[12] Galaskiewicz, J., \& Wasserman, S. (1989). Mimetic Processes Within an Interorganizational Field: An Empirical Test. Administrative Science Quarterly, 34(3), 454-479. https://doi.org/ 10.2307/23 93153

[13] Giles, J., Park, A., \& Cai, F. (2006). Reemployment of dislocated workers in urban China: The roles of information and incentives. Journal of Comparative
Economics, 34(3), 582-607. https://doi.org/ 10.1016/j.jce.2006.06.006

[14] Jing, H. (2012). Ren yi li zhi xin yu zhonghua wenhua de hexin jiazhi (Humanism, Justice, Etiquette, Wisdom, Faith and the Coral Values in China Culture), (4), 188-194.

[15] Lovett, S., Simmons, L. C., \& Kali, R. (1999). Guanxi versus the market: Ethics and efficiency. Journal of International Business Studies, 30(2), 231-247. https://doi.org/10.1057/palgrave.jibs. 84900 68

[16] Luo, Y. (2001). Antecedents and Consequences of Personal Attachment in Cross-cultural Cooperative Ventures. Administrative Science Quarterly, 46(2), 177-201. https://doi.org/10. 2307/2667085

[17] Luo, Y., Huang, Y., \& Wang, S. L. (2012). Guanxi and organizational performance: A meta-analysis. Management and Organization Review, 8(1), 139-172. https: //doi.org/10.1111/j.1740-8784.2011.00273. $\mathrm{x}$

[18] Luo, J. Der. (2011). Guanxi Revisited: An Exploratory Study of Familiar Ties in a Chinese Workplace. Management and Organization Review, 7(2), 329-351. https://doi.org/10.1111/j.1740-8784.2011.0 0230.x

[19] Park, S. H., \& Luo, Y. (2001). Guanxi and organizational dynamics: Organizational networking in Chinese firms. Strategic Management Journal, 22(5),455-477. https://doi.org/10.1002/smj. 167

[20] Peng, M. W., \& Luo, Y. (2000). Managerial ties and firm performance in a transition economy: The nature of a micro-macro link. Academy of Management Journal, 43(3), 486-501. https://doi.org/ 10.2307/1556406

[21] Powell, W. (1990). Neither Market nor Hierarchy: Network Forms of Organization. Research in Organizational Behavior, Vol. 12.https://doi.org/10.1590/S1415-6555200 3000200016

[22] Tan, D., \& Snell, R. S. (2002). The third eye: Exploring guanxi and relational morality in the workplace. Journal of Business Ethics. https://doi.org/10.1023/A:1021217027814 
Positive Effect or Negative Effect? Judging the Social Impact of Guanxi in the Perspective of Traditional China Culture

[23] Wang, C. L. (2007). Guanxi vs. relationship marketing: Exploring underlying differences. Industrial Marketing Management, 36(1), 81-86. https://doi.org/ 10.1016/j.indmarman.2005.08. 002

[24] Xiao, Z., Tsui, A. S., Administrative, S., Quarterly, S., \& Mar, N. (2007). When brokers may not work: The cultural contingency of social capital in Chinese high-tech firms. Administrative Science Quarterly, 52(1), 1-31. https://doi.org/10.2189/asqu.52.1.1

[25] Yeung, I. Y. M., \& Tung, R. L. (1996). Achieving business success in Confucian societies: The importance of guanxi (connections). Organizational Dynamics, 25, 54-65. https://doi.org/10.1016/S00902616(96)90025-X

[26] Yum, J. O. (1988). The impact of Confucianism on interpersonal relationships and communication patterns in east Asia. Communication Monographs, 55(4), 374-388. https://doi.org/10.1080/ 03637758809376178

[27] Zhang, X., \& Li, G. (2003). Does guanxi matter to nonfarm employment? Journal of Comparative Economics, 31(2), 315-331. https://doi.org/10.1016/S0147-5967(03)000 19-2

[28] Zhang, Y., \& Zhang, Z. (2006). Guanxi and organizational dynamics in China: A link between individual and organizational levels. Journal of Business Ethics, 67(4), 375-392. https://doi.org/10.1007/s10551-0 06-9031-7

\section{AUTHORS' BIOGRAPHY}

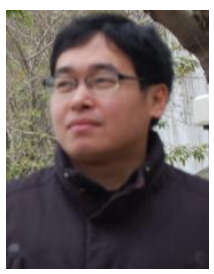

Ruihui Han, He earned his doctoral degree in Zhongshan University in 2008. $\mathrm{He}$ is interested in culture studies.

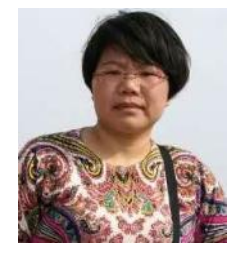

Qingdian Han, She earned her doctoral degree in Fujian Agriculture and Forestry University in 2008. She works in Linyi University.

Citation: Ruihui, Han, and Han Qingdian. "Positive Effect or Negative Effect? Judging the Social Impact of Guanxi in the Perspective of Traditional China Culture." International Journal of Research in Humanities and Social Studies, vol 4, no. 4, 2017, pp. 1-8.

Copyright: () 2017 Ruihui Han, et al. This is an open-access article distributed under the terms of the Creative Commons Attribution License, which permits unrestricted use, distribution, and reproduction in any medium, provided the original author and source are credited. 